Revista Destaques Acadêmicos, Lajeado, v. 12, n. 1, 2020. ISSN 2176-3070

DOI: http://dx.doi.org/10.22410/issn.2176-3070.v12i1a2020.2437

http://www.univates.br/revistas

\title{
PROPOSTA DE IMPLANTAÇÃO DE UM PLANEJAMENTO ORÇAMENTÁRIO EMPRESARIAL: ESTUDO DE CASO EM UMA EMPRESA DE PEQUENO PORTE DO SEGMENTO DE PRESTAÇÃO DE SERVIÇOS TECNOLÓGICOS
}

\author{
Mirian Denise Buss ${ }^{1}$, Citania Aparecida Pilatti Bortoluzzi ${ }^{2}$
}

\begin{abstract}
Resumo: Em um mercado tão competitivo, conciliado com a instabilidade econômica, é preciso que os gestores acompanhem cada vez mais de perto o andamento de seu negócio, e tenham estratégias para eventuais problemas que possam surgir, a fim de poder resolvê-los e também poder manter-se no mercado. Desta forma, realizar um planejamento orçamentário é fundamental para toda e qualquer empresa ter uma visão da organização através de números, e por meio destes, identificar se a mesma está gerando lucros ou prejuízos. Se a empresa precisa tomar atitudes diferentes para ter continuidade, expandir e aumentar a lucratividade. E cada plano deve ser adaptado de acordo com a realidade de cada negócio. Neste sentido, o presente trabalho visou analisar a percepção dos gestores e também dos funcionários, em relação a importância do planejamento orçamentário, por meio da aplicação de um questionário, em uma empresa de pequeno porte, que ainda não utiliza o processo orçamentário. Com as respostas obtidas nesse questionário, foi proposto um fluxo de caixa projetado.
\end{abstract}

Palavras-chave: Planejamento orçamentário empresarial. Tomada de decisão. Fluxo de caixa.

\section{INTRODUÇÃO}

Nos últimos anos, têm-se visto a criação de muitas empresas desenvolvedoras de software para os mais diversos segmentos de mercado, e o crescimento enorme de muitas já existentes. Algumas dessas empresas tem pouco tempo de mercado, mas já possuem um valor monetário muito superior a outras empresas com marcas já consolidadas (SIMBER TECNOLOGIA, 2013).

O mercado de desenvolvimento de software está em pleno crescimento. A cada dia novas tecnologias surgem e ao mesmo tempo outras acabam

1 Bacharel em Administração pela UNOCHAPECÓ

2 Bacharel em Ciências Contábeis pela FACEPAL 
se tornando obsoletas então, é preciso inovar, buscar novas ideias, novos programas e soluções. Mas ao mesmo tempo em que se busca essas inovações para disponibilizar melhores produtos e/ou serviços, é preciso também que os empreendedores se preocupem com o planejamento da empresa (SIMBER TECNOLOGIA, 2013).

Diante destas atividades desenvolvidas, muitos empresários e suas equipes acabam não realizando um planejamento orçamentário. Isso se dá, pois muitas vezes acham que este só deve ser realizado por empresas de grande porte, sendo totalmente desnecessário perder tempo com planejamento em pequenas empresas. Engana-se o empresário que ainda pensa assim, pois isso leva muitas empresas a fecharem suas portas. Seja uma pequena ou grande empresa, o planejamento orçamentário é fundamental para garantir a saúde empresarial e assim, manter a permanência e o crescimento desta (QUANTOSOBRA, 2018)

O planejamento orçamentário não deve apenas ser executado em grandes companhias. Independentemente de seu faturamento, devem manter uma gestão voltada a orçar, planejar e executar, pois o orçamento é uma ferramenta preciosa para a tomada de decisões desde que bem realizado com metas claras e objetivas que reflitam a curto e longo prazo (ATITUDE E NEGÓCIO, 2018).

Diante do exposto tem-se a seguinte questão problema: Como a elaboração de um planejamento orçamentário empresarial pode contribuir para tomada de decisões em uma empresa de pequeno porte?

Para responder a questão problema o estudo tem por objetivo geral, propor um planejamento orçamentário empresarial para contribuir na tomada de decisões em uma empresa de pequeno porte.

Seja nas empresas ou mesmo na vida pessoal, realizar um planejamento é essencial para se alcançar objetivos e/ou metas. Mas para alcançar o objetivo mais rapidamente, é preciso colocá-lo em prática e traçar um plano de ação, pois isso ajuda na organização do tempo e do foco. O planejamento orçamentário é importante na gestão das empresas, pois através dele é possível entender qual a situação econômica do negócio. Dessa forma, se tem uma diretriz para se tomar as decisões de melhorias no gerenciamento dos recursos, bem como oferecer mais controle e possíveis previsões de gastos e mais propriedade para solucionar problemas diversos. Assim, o intuito deste trabalho é buscar maior compreensão sobre o planejamento orçamentário e propor um planejamento para a empresa Gama Tecnologia, a fim de analisar seu nível de contribuição como ferramenta de gestão no apoio a tomada de decisões.

\section{FUNDAMENTAÇÃO TEÓRICA}

Neste capítulo encontram-se os principais conceitos teóricos necessários para o desenvolvimento deste trabalho. Iniciando pela definição de orçamento 
empresarial, em seguida, explicando como organizar, quais as etapas do orçamento empresarial, bem como suas vantagens e também as limitações.

\subsection{Orçamento empresarial}

O ambiente empresarial está sujeito constantemente a ameaças bem como a transformações em seu ambiente. Isso ocorre em função das alterações de legislação, estratégias de concorrentes e fatores econômicos do setor de atuação (HELENO, 2018).

Conforme Dourado (2018), o ramo de prestação de serviços é a execução de trabalhos contratados por terceiros com fim produtivo ou lucrativo. No estudo em questão, trata-se de prestação de serviços por uma empresa de software, que tem por objetivo desenvolver soluções para auxiliar as empresas no processamento diário de suas informações. Os resultados desta prestação de serviços é a organização dos processos da empresa.

Administrar uma empresa sem conhecer seu gastos, sem ter estimativa de vendas, sazonalidade dos produtos ou não saber o nível de endividamento pode comprometer a empresa e até mesmo leva-la a falência. Por isso, cada vez mais o orçamento empresarial tem se tornado algo indispensável nas empresas, já que é por meio dele que a gestão da empresa sabe quanto dinheiro tem para pagar suas contas, para investir e o quanto e aonde deve reduzir gastos para atingir sua meta maior, que é o lucro. O orçamento é uma ferramenta que auxilia a empresa a pôr em prática um plano de ação (PADOVEZE, 2012).

O orçamento empresarial pode ser definido de várias maneiras. Para Frezatti (2009), um orçamento empresarial proporciona meios para que se possa avaliar o desempenho dos setores dentro da empresa. Por meio dele, é possível prestar contas das atividades com os resultados obtidos, pois comparam-se os valores que foram planejados, com os valores que de fato aconteceram.

Orçamento empresarial é um instrumento de programação que relaciona os fluxos de ingressos dos recursos à sua aplicação nas atividades organizacionais, a fim de estabelecer um plano de ação futuro, orçando receitas que serão obtidas e as despesas que incidirão na sua execução. (MACEDO, 2014, p.81).

De acordo com Padoveze (2012), o orçamento é expresso de forma quantitativa, ou seja, é preciso colocar quantidades e valores, de todos os elementos que farão parte do plano de ação.

$\mathrm{O}$ orçamento pode ser classificado em longo prazo ou curto prazo. $\mathrm{O}$ orçamento de longo prazo é importante nos casos em que se leva em conta as premissas de crescimento e expansão. Além disso, considera-se também os objetivos estratégicos da empresa. No orçamento de curto prazo, busca-se quantificar os planos da empresa por meio de metas, determinando-se os termos 
de utilização de recursos, o que fazer, quando e como fazer (FIGUEIREDO; CAGGIANO, 2017).

\subsection{Organização do orçamento}

O processo orçamentário exige organização. Nas grandes empresas, normalmente o orçamento fica sob a responsabilidade de uma comissão orçamentária, onde esta tem o papel de coordenar e controlar o processo orçamentário para toda a empresa (FIGUEIREDO; CAGGIANO, 2017). Essa comissão solicita as estimativas para os gestores divisionais, os quais se baseiam em informações repassadas pelos seus subordinados, ou seja, as informações vem de baixo para cima. Então, essas informações retornam para a comissão orçamentária, a qual coordena as mesmas e resolve qualquer dúvida que tenha surgido, e apresenta à diretoria para aprovação (FIGUEIREDO; CAGGIANO, 2017).

De acordo com Lunkes (2008), o responsável por organizar o orçamento pode ser um gerente que coordena uma unidade e todos os seus empregados. Conforme a estrutura da empresa, o orçamento pode ser elaborado por departamentos. $\mathrm{Ou}$ ainda, o orçamento pode ser coordenado por unidades menores, onde um empregado passa a ser o responsável por monitorar e controlar uma conta contábil.

Desta forma, pode-se perceber que não há só uma maneira de organizar o orçamento. Também, a responsabilidade não precisa ser somente definida por departamento visto que ela pode ser determinada por meio da atividade, do processo, da unidade e até mesmo em função de uma conta contábil (LUNKES, 2008).

\subsection{Etapas do processo orçamentário}

O processo de vendas de uma empresa sempre tem um papel fundamental, visto que é a porta de entrada de recursos. Segundo Oliveira (2014), o orçamento de vendas deve ser pensado e elaborado, sempre que possível, para um curto e para um longo prazo. Isso se dá pelo fato que no curto prazo deve ser considerado o mês corrente bem como bimestre/trimestre/ semestre e ano. Já no orçamento a longo prazo é importante o planejamento para os anos seguintes.

De acordo com Sanvicente e Santos (2008), precisa sempre ser considerada no orçamento de vendas a existência de restrições internas da empresa, a exemplo da capacidade produtiva, de sua estrutura administrativa (espaço físico, etc.), do treinamento aos seus colaboradores bem como outros itens. Ainda, precisa ser avaliada a existência de restrições externas que a empresa pode ter, podendo as mesmas ser referente a políticas, legislações governamentais, oferta de mão de obra e também ações dos concorrentes no mercado. 
Quando a organização é baseada em serviços, principalmente em software, o processo comercial de venda também é importante, porém outros também precisam ser considerados com ênfase. Um dos primeiros itens que precisam ser considerados, conforme Figueiredo e Caggiano (2017) é a avaliação dos limites do plano, que podem ser a capacidade produtiva da organização, condições de mercado que possam impedir determinadas ações e ainda os recursos financeiros que estarão disponíveis.

Ainda, de acordo com Souza (2014), o orçamento de vendas é uma peça importante dentro do sistema orçamentário, visto que é por meio dela que são elaborados os planejamentos da empresa bem como os demais orçamentos necessários de investimentos em novos produtos e equipamentos para desenvolvimento.

De acordo com Padoveze e Taranto (2009), o orçamento de investimento deve obrigatoriamente trabalhar baseado nas aquisições necessárias para a empresa - nesse caso equipamentos para desenvolvimento e teste de software - bem como também um planejamento voltado para aquisições de ativos imobilizado para a empresa, quando possui essa necessidade. Ainda, "o orçamento de investimento visa determinar os valores de aquisições e baixas do ativo permanente, bem como apurar as cotas de depreciação, exaustão e amortização" (HOJI, 2014, p. 457).

Outra etapa importante para ser considerada no processo orçamentário é voltada à produção. Para Hoji (2014) o orçamento de produção deve determinar, a partir das vendas realizadas ou de um planejamento de vendas realizado, qual a quantidade de um ou mais produtos que precisa ser produzida. Considerando serviços de software, tal orçamento precisa considerar o planejamento das necessidades de equipamentos, mão de obra e estrutura que precisam estar disponíveis no momento de desenvolver as soluções.

Dependendo do mercado de atuação da empresa e do tipo de solução que desenvolve, são necessários equipamentos para a realização do desenvolvimento e também a realização dos testes dos mesmos, o que precisa sempre ser considerado. A realização de um planejamento de aquisição de equipamentos, a partir do momento da existência de um orçamento de vendas ou projeto a ser trabalhado, já deverá contemplar as atividades que a organização irá executar diante dos seus clientes (HOJI 2014).

De acordo com Lunkes (2008), para cada elemento envolvido na produção deve ser prevista uma base no orçamento. Dessa forma, para o desenvolvimento das atividades nas organizações de serviços de software precisa estar definido no planejamento quais os fatores diretamente envolvidos, neste caso principalmente a mão de obra, juntamente com custos que serão diretos ou indiretos no desenvolvimento das soluções. 


\subsection{Vantagens e limitações do orçamento}

O processo orçamentário proporciona diversas vantagens para a empresa, dentre elas pode-se citar: a definição previa dos objetivos; a melhora na comunicação e integração da organização; ele leva os colaboradores a focarem no futuro; forma uma estrutura com atribuições de responsabilidade; gera maior eficiência, eficácia e economia nas operações; aumenta a coordenação e o controle das atividades para atingir as metas e motiva os colaboradores ao longo da organização, onde as metas podem servir de base para uma remuneração variável (LUNKES, 2008).

Sanvicente e Santos (2008) complementam que o orçamento também traz a vantagem de reduzir o envolvimento dos altos administradores nas operações diárias, já que poderes e autoridades são delegados. Além disso, o orçamento tende a melhorar a utilização dos recursos que a empresa tem disponível, para que assim, sejam alcançados os seus objetivos.

Apesar das vantagens, o orçamento também pode ter algumas limitações. Conforme Lunkes (2008) essas limitações podem ser: a inflexibilidade do processo orçamentário, que não permite alterações no decorrer do período; tempo de elaboração muito longo; ações e reações indesejadas; visão apenas financeira; desmotivação para alguns colaboradores, condicionado as forças de poder da organização. Essas limitações podem ser maiores ou menores, dependendo do processo orçamentário que a empresa optar por utilizar.

\section{METODOLOGIA}

Este estudo teve como objetivo principal, propor um planejamento orçamentário empresarial para contribuir na tomada de decisões em uma empresa de pequeno porte e, para ser possível sua realização, o mesmo foi desenvolvido pelo método indutivo.

Segundo Marconi e Lakatos (2010), o método indutivo se baseia na indução, ou seja, é um processo mental que para chegar à verdade universal ou referencial, parte de dados particulares, comprovados. Neste método, três etapas são necessárias: a observação dos fenômenos, para descobrir as suas causas; a descoberta da relação entre eles, por meio da comparação, identificando a relação constante entre eles; e a generalização da relação, onde a relação encontrada é generalizada entre os fenômenos e fatos semelhantes.

Para Santos (2016, p. 189), o método indutivo "constitui-se na observação e experimentação dos fenômenos estudados e obriga o pesquisador a seguir as etapas de: experimentação, criação de hipóteses, repetição, teste das hipóteses, generalização e formulação de leis".

Com relação ao delineamento, este estudo classifica- se como estudo de caso. De acordo com Yin (2005, p. 20) o estudo de caso define-se "Como estratégia de pesquisa, utiliza-se o estudo de caso em muitas situações, para contribuir 
com o conhecimento que temos dos fenômenos, individuais, organizacionais, sociais, políticos e de grupo, além de outros fenômenos relacionados".

O instrumento de coleta de dados utilizado foi o questionário. Conforme Santos (2016), o questionário é composto por uma série de itens bem ordenados e bem apresentados, com perguntas relacionadas a um tema central, que são respondidas sem a presença do entrevistador. A técnica de análise e interpretação de dados utilizada neste estudo classifica- se como qualitativa. De acordo com Figueiredo (2014, p. 44) "Qualitativo é a interpretação dos dados levando- se em consideração seu conteúdo, a forma de apresentação adotada na maioria dos casos é a elaboração de textos".

\section{APRESENTAÇÃO E ANÁLISE DOS RESULTADOS}

O estudo de caso foi realizado em uma empresa prestadora de serviços tecnológicos, que desenvolve softwares customizados para atender áreas comerciais ou equipes que desempenham atividades externas.

A Gama Tecnologia está localizada em Chapecó - SC, e foi fundada no ano de 2000. Desde o seu surgimento, o objetivo foi desenvolver soluções que agregassem valor em seus clientes e a definição no nicho de trabalho se deu logo em seus primeiros anos de atuação. A Gama Tecnologia está se expandindo rapidamente através dos 3 estados do Sul, como empresa de tecnologia e seus serviços de mobilidade, com atuação em grandes empresas.

Para este estudo, foi aplicado um questionário no mês de setembro de 2019, com todos os colaboradores, sócios e o contador da empresa, totalizando 14 pessoas. O questionário foi aplicado por meio do Google docs, e elaborado com base no artigo de Lima, (2014).

Primeiramente, buscou-se identificar o cargo ocupado pelos respondentes, apresentado no Gráfico 1. 
Gráfico 1 - Função que desempenha

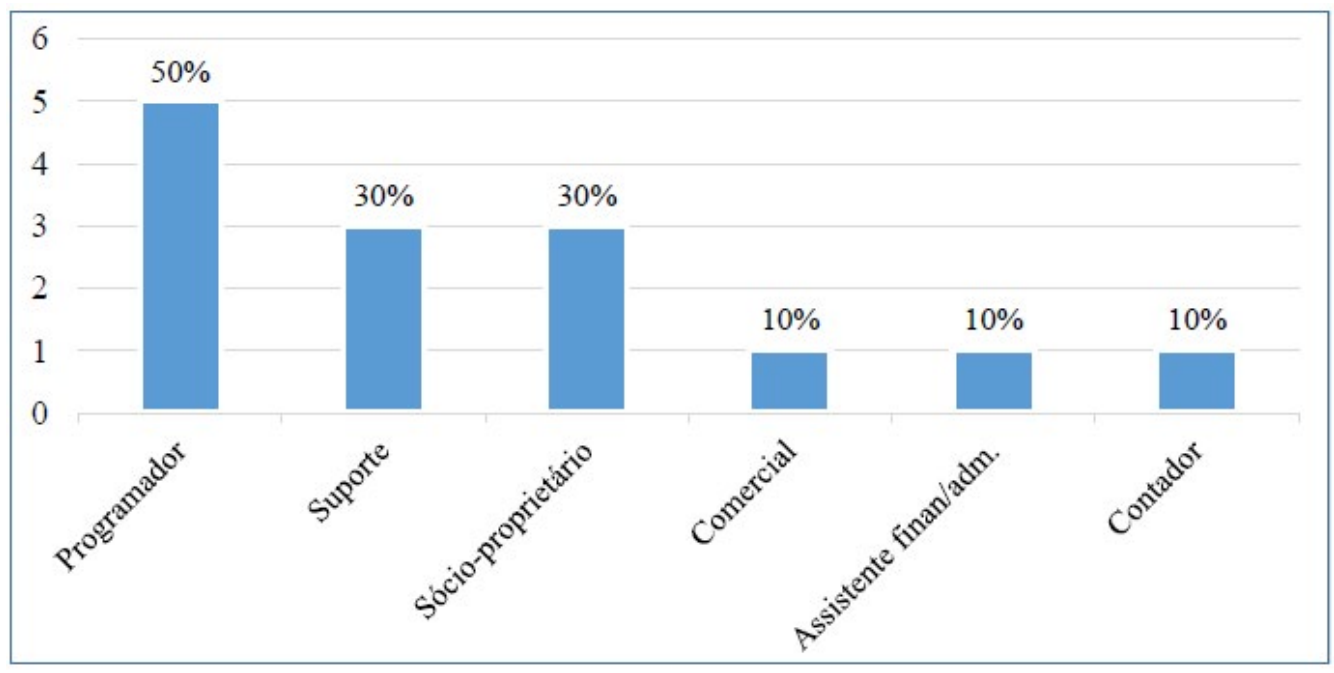

Fonte: Dados da pesquisa (2019)

Embora a amostra possa ser considerada pequena, é relevante apresentar a formação orgânica da empresa. Deste modo é possível verificar pelo Gráfico 1, que 5 dos colaboradores exercem a função de programadores, 3 colaboradores estão na área de suporte, 1 na área comercial, 1 na área financeira, 1 na contabilidade e os outros 3 caracterizam-se como sócios proprietários.

Em seguida buscou-se verificar qual a percepção sobre a importância do processo orçamentário na empresa, demonstrado no Gráfico 2.

Gráfico 2 - Importância do processo orçamentário

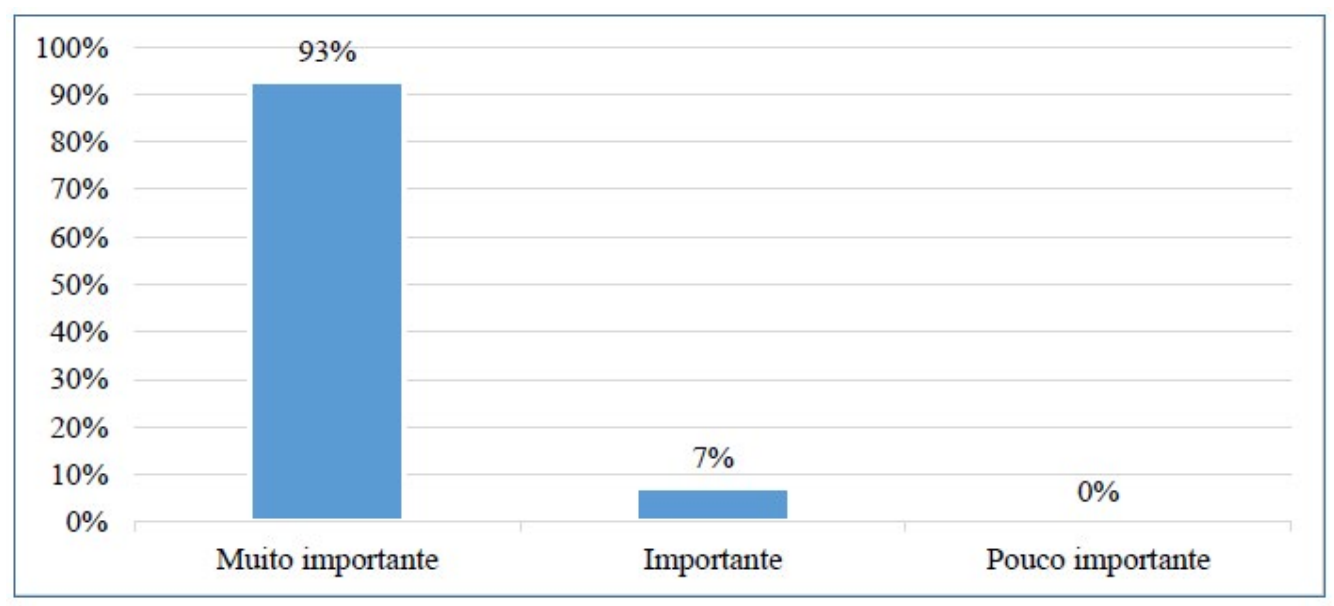

Fonte: Dados da pesquisa (2019) 
Verifica-se por meio do Gráfico 2, que 93\% dos respondentes avaliaram como sendo muito importante o processo orçamentário e apenas $7 \%$ dos respondentes considerou como importante. A opção pouco importante não foi citada tendo então $0 \%$.

Conforme apresentado na base teórica deste artigo, alguns itens são relevantes para a construção e análise do orçamento. Diante disso, no Gráfico 3, é possível verificar alguns itens que os colaboradores julgam importante.

Gráfico 3 - Itens que o processo orçamentário contribui na tomada de decisões

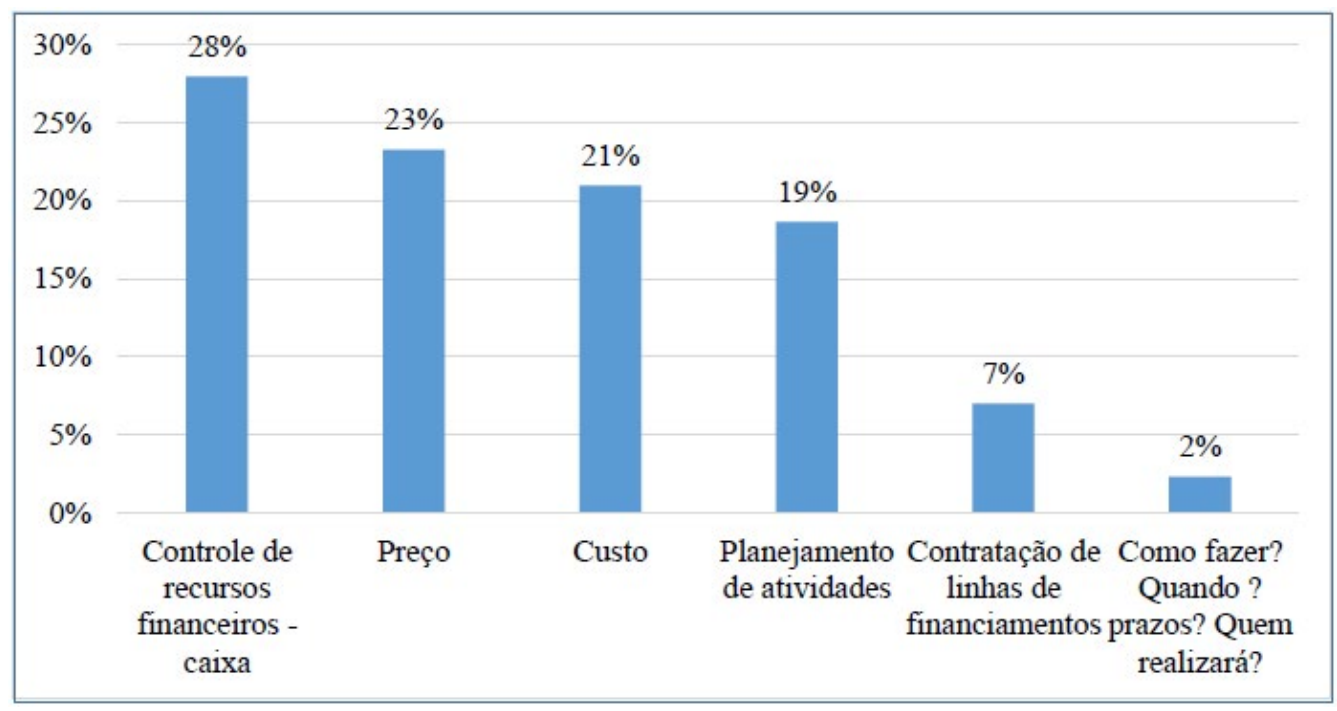

Fonte: Dados da pesquisa (2019)

Por meio do Gráfico 3, nota-se que quando questionados sobre quais os itens que o processo orçamentário contribui na tomada de decisões, sendo esta uma questão de múltipla escolha, o controle de recursos financeiros - caixa, foi o item que obteve a maior indicação representando $28 \%$ das respostas. Em seguida, foram elencados o preço com $23 \%$, custo com $21 \%$, planejamento de atividades com $19 \%$ e a contratação de linhas de financiamento com $7 \%$ das respostas. Apenas $2 \%$ sugeriu definir como fazer, quando, prazos e quem realizará.

No Gráfico 4, é possível verificar quais são os itens que mais dificultam a implantação e utilização do processo orçamentário por uma empresa. 
Gráfico 4 - Dificuldades de implantação e utilização do processo orçamentário

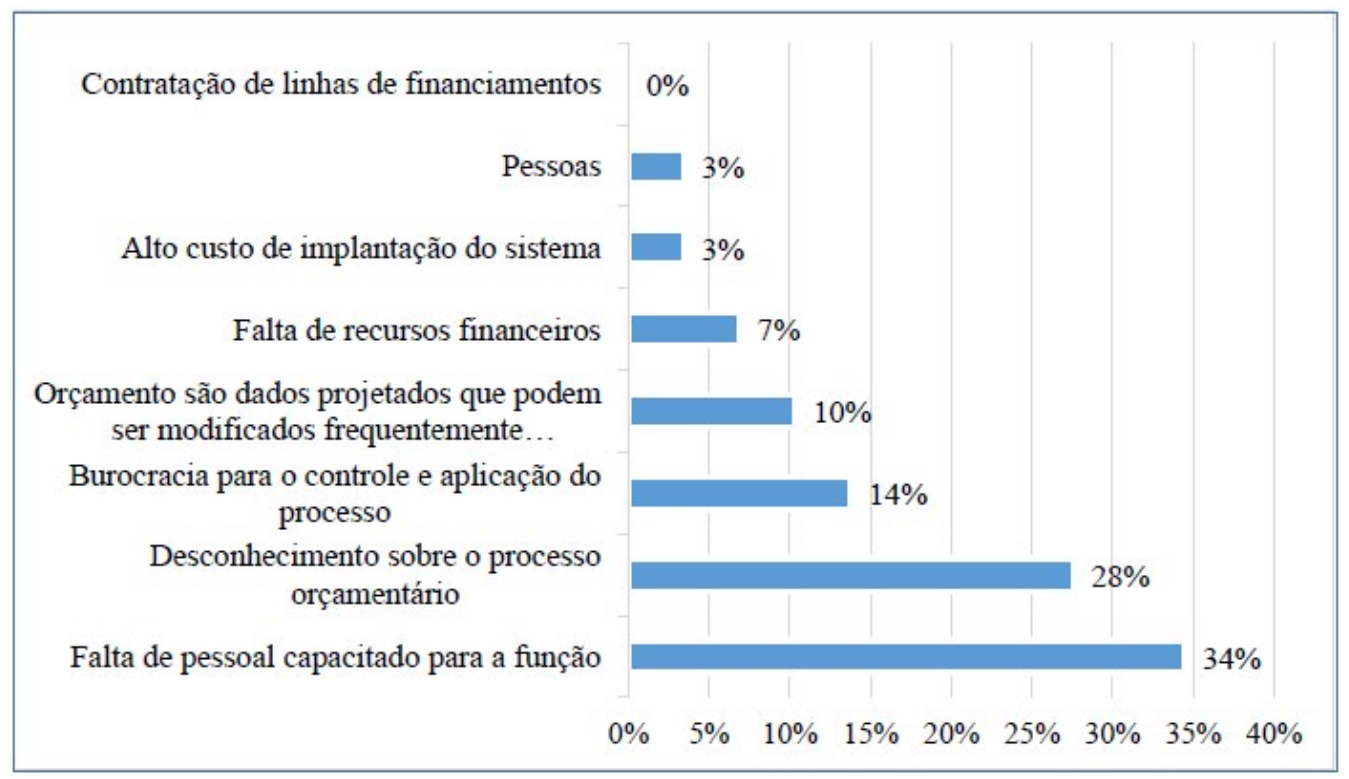

Fonte: Dados da pesquisa (2019)

Conforme o Gráfico 4, referente ao questionamento sobre os fatores que dificultam a implantação e utilização do processo orçamentário por uma empresa, a maioria dos respondentes considerou a falta de pessoal capacitado para a função, representando $34 \%$ das respostas. Em seguida, foram elencados o desconhecimento sobre o processo orçamentário com $28 \%$, a burocracia com $14 \%$, orçamento representante $10 \%$ e falta de recursos financeiros representante $7 \%$. Ainda foram citados o alto custo e pessoas com 3\% cada. A opção de contratação de linhas de financiamento não foi citada por nenhum respondente.

Em seguida, o Gráfico 5 demonstra o que pode contribuir para a empresa, o uso do processo orçamentário. 
Gráfico 5 - Contribuição do processo orçamentário

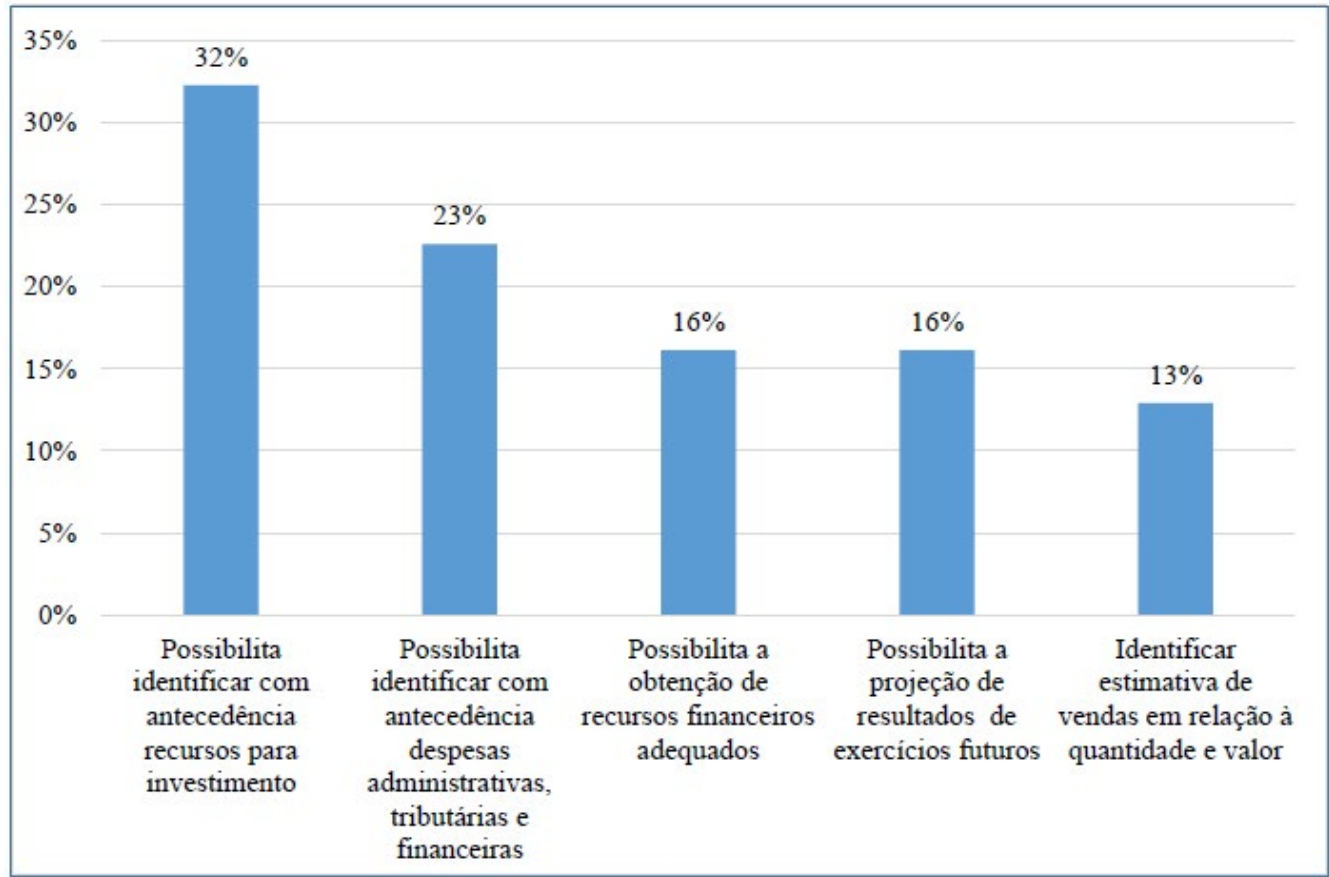

Fonte: Dados da pesquisa (2019)

Sobre o questionamento da contribuição do processo orçamentário para a empresa, verifica-se por meio do Gráfico 5 que $32 \%$ dos respondentes, ou seja, a maioria, acreditam que o orçamento possibilita identificar com antecedência recursos para investimento. Em seguida, 23 \% dos respondentes consideram que possibilita identificar com antecedência as despesas administrativas, tributárias e financeiras. Ainda, $16 \%$ dos respondentes apontou que possibilita a obtenção de recursos financeiros e possibilita a projeção de resultados futuros e por último, $13 \%$ responderam que tem-se a estimativa de vendas em relação à quantidade e valor.

No Gráfico 6, é possível identificar em qual setor e/ou atividade da empresa que deve ser implementado primeiro o processo orçamentário. 
Gráfico 6 - Implantação do processo orçamentário (Setor)

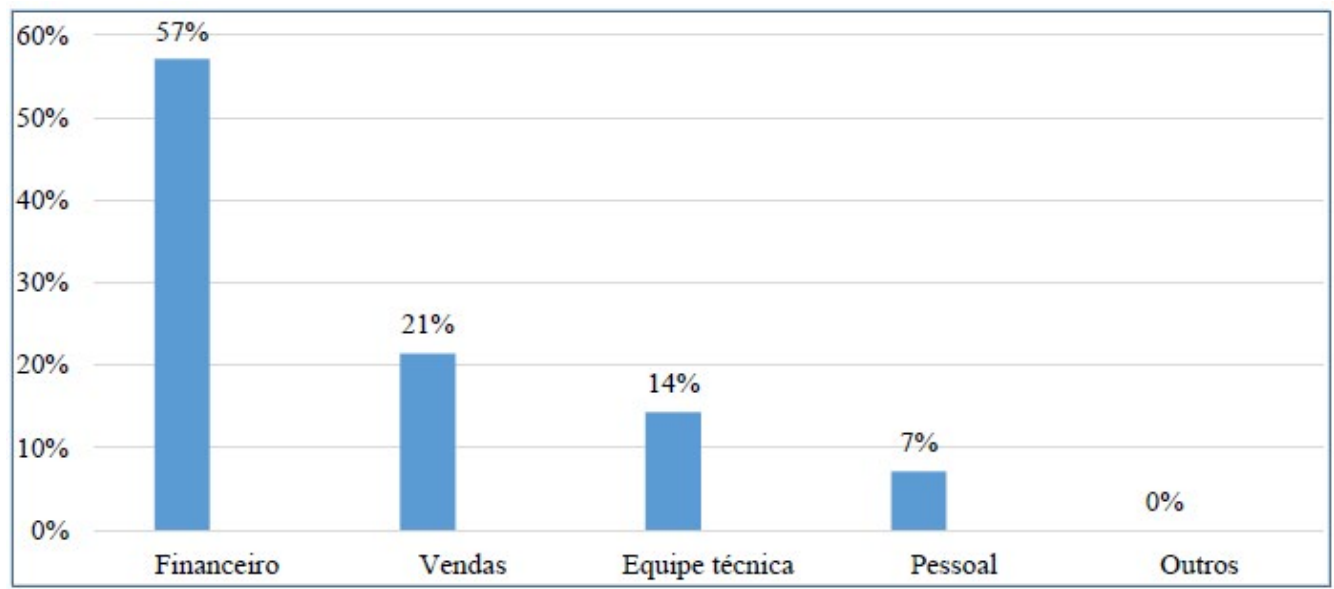

Fonte: Dados da pesquisa (2019)

Em relação ao setor e/ou atividade da empresa que deve ser implementado primeiramente o processo orçamentário, o Gráfico 6 demonstra que $57 \%$ dos respondentes indicaram o setor financeiro. Em seguida foram elencados os setores de vendas com $21 \%$ das respostas, a equipe técnica com $14 \%$ das respostas enquanto $7 \%$ responderam que deve ser o setor pessoal.

A seguir, o Gráfico 7 indica se a empresa adota o processo orçamentário na tomada de decisão.

Gráfico 7 - A empresa adota o processo orçamentário para o controle e tomada de decisões

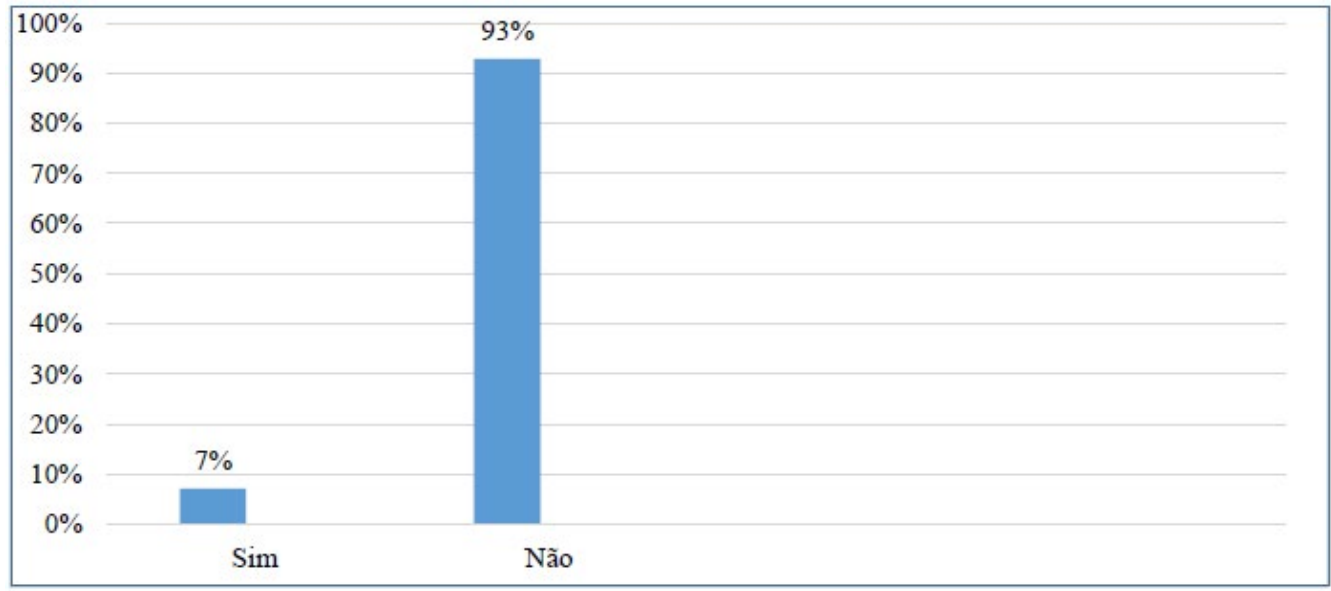

Fonte: Dados da pesquisa (2019) 
O Gráfico 7 trata sobre a questão se a empresa adota o processo orçamentário, e 93\% responderam que não, e 7\% responderam que sim. Mas conforme relatado pela empresa, a mesma realmente não realiza processo orçamentário, logo, houve um equívoco nesta resposta.

Na sequência o Gráfico 8 indica a disponibilidade em receber orientações do processo orçamentário.

Gráfico 8 - Disponibilidade para receber orientações e suporte para implantação do processo orçamentário

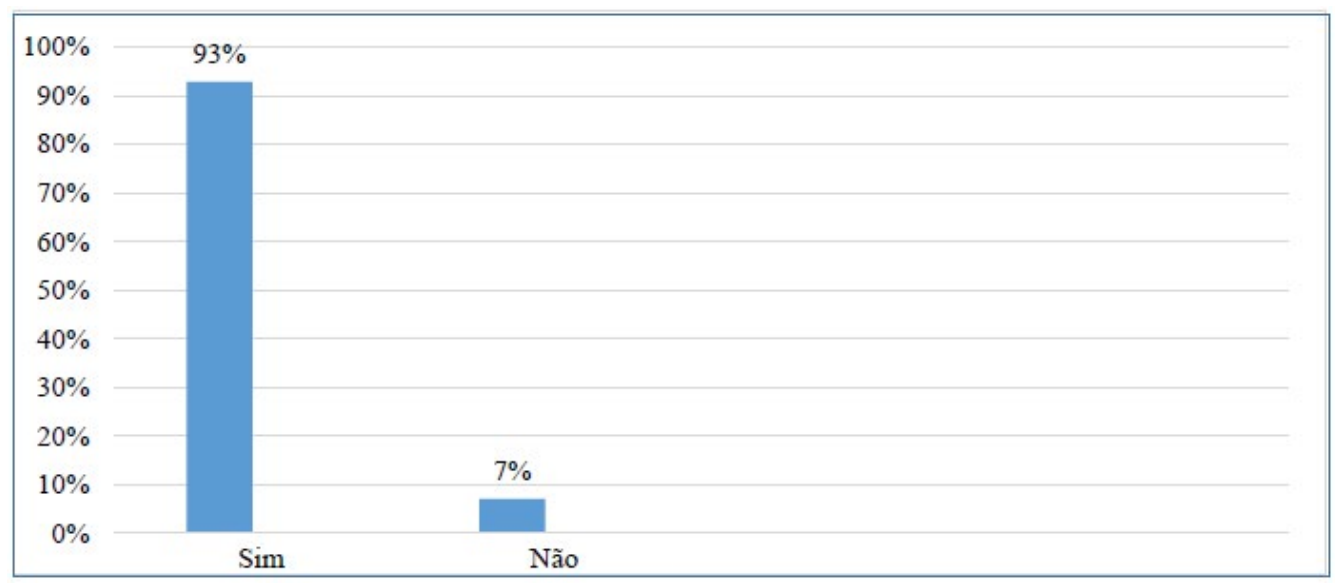

Fonte: Dados da pesquisa (2019)

Ao questionamento da disponibilidade e interesse em receber informações para implantação do processo orçamentário, $93 \%$ dos respondentes demonstraram interesse, e apenas $7 \%$, sendo representado por uma pessoa, não gostaria de receber esse auxílio.

Através das respostas obtidas no questionário, é possível verificar que o processo orçamentário é considerado muito importante para a organização, e conforme as respostas dos Gráficos 3, 4 e 6, neste momento, este processo deve ser primeiramente implementado no setor financeiro da empresa.

\subsection{Proposta dos procedimentos a serem implantados na empresa}

Conforme identificado anteriormente, com a aplicação e análise do questionário, verificou-se que a proposta para implantação de um orçamento, deve ocorrer no departamento financeiro. Desta forma, foi elaborado um orçamento de fluxo de caixa para o $1^{\circ}$ semestre de 2020, por meio de projeções de receitas, custos e despesas. Esta proposta foi baseada no estudo de Weber (2014). 
A utilização do fluxo de caixa, é uma ferramenta essencial para acompanhar a saúde financeira de uma empresa. É uma das maneiras mais eficazes de se obter dados precisos sobre a real situação financeira da empresa. O fluxo de caixa pode ser realizado por meio de planilhas, sistemas ou até mesmo no papel, mas o importante mesmo, são as informações constantes nele, as quais servem de base para a tomada de decisões dos gestores.

Na realização de um fluxo de caixa projetado, estimam-se valores de entradas e saídas, baseados em dados passados, para que assim, seja projetado um cenário futuro. Por meio do fluxo de caixa projetado, é possível saber antecipadamente se a empresa precisará de financiamento ou se terá sobras de receitas que poderão ser aplicadas, e além disso, também pode se organizar melhor em questão de melhores datas para efetuar pagamentos de fornecedores.

Para a realização da projeção do fluxo de caixa, primeiramente foi projetado os recebimentos que a empresa terá mês a mês no $1^{\circ}$ semestre de 2020. Os dados aqui apresentados não são reais, pois a empresa não permitiu a abertura dessas informações, mas são valores aproximados da realidade, baseados no que a empresa já tem como certo por receber.

Os recebimentos ocorrem de duas maneiras: por parcelas mensais com valores fixos de recorrência, quando o cliente paga para manter a utilização do sistema e, por venda de projeto, onde os valores são faturados em uma única vez. Ambos recebimentos são realizados através de boletos. O Quadro 1 demonstra a projeção dos recebimentos das mensalidades provenientes dos serviços contratados, que serão desenvolvidos em planilhas eletrônicas.

Quadro 1 - Recebimento Mensal

\begin{tabular}{|l|l|c|c|c|c|c|c|}
\hline Meses & $\begin{array}{l}\text { Valores a } \\
\text { Receber }\end{array}$ & Janeiro & Fevereiro & Março & Abril & Maio & Junho \\
\hline Janeiro & $155.000,00$ & $155.000,00$ & & & & & \\
\hline Fevereiro & $175.000,00$ & & $175.000,00$ & & & & \\
\hline Março & $150.000,00$ & & & $150.000,00$ & & & \\
\hline Abril & $150.000,00$ & & & & $150.000,00$ & & \\
\hline Maio & $140.000,00$ & & & & & $140.000,00$ & \\
\hline Junho & $140.000,00$ & & & & & & $140.000,00$ \\
\hline Total & $\mathbf{9 1 0 . 0 0 0 , 0 0}$ & $\mathbf{1 5 5 . 0 0 0 , 0 0}$ & $\mathbf{1 7 5 . 0 0 0 , 0 0}$ & $\mathbf{1 5 0 . 0 0 0 , 0 0}$ & $\mathbf{1 5 0 . 0 0 0 , 0 0}$ & $\mathbf{1 4 0 . 0 0 0 , 0 0}$ & $\mathbf{1 4 0 . 0 0 0 , 0 0}$ \\
\hline
\end{tabular}

Fonte: Dados projetados pelo autor (2019)

Conforme pode-se observar, o Quadro 1 traz uma projeção de R $\$$ $910.000,00$ de receitas para o $1^{\circ}$ semestre de 2020. Como os recebimentos são por meio de boleto, os faturamentos ocorrem no final do mês, com prazo de 15 dias, assim, o recebimento ocorre no mês seguinte. Também há recebimento de faturamentos anteriores a dezembro, referente a vendas parceladas. 
Após as receitas, foi projetado o orçamento do fluxo de caixa, com as devidas receitas e despesas. Primeiramente, em janeiro de 2020 iniciouse o caixa com um saldo de $\mathrm{R} \$ 3.000,00$, e em seguida foram somados todos os recebimentos do mês de janeiro, e depois foram descontados os valores referente a custos e despesas do mês, conforme o Quadro 2.

Para projeção de todas as despesas e também das receitas financeiras, utilizou-se uma média dos 3 semestres no mesmo período, considerando algumas variáveis ajustadas para a realidade atual da empresa. Sobre cada uma das despesas foi aplicado o percentual correspondente conforme o histórico, chegando-se dessa forma aos valores apresentados no Quadro 2.

Conforme pode ser identificado no Quadro 2, foram projetadas as despesas com Fornecedores, Despesas com Pessoal, Pró-labore, Taxas e Contribuições, Impostos e Despesas Gerais. Todos os itens foram totalizados nos Desembolsos que, subtraídos dos Ingressos e do Saldo Inicial resultaram no Saldo Líquido do mês. Nos Ingressos não Operacionais, foram considerados os Empréstimos Obtidos, Resgate de Aplicação, Receita Financeira e Taxa de Juros Empréstimos. Conforme a projeção da empresa, mensalmente haverá apenas o resgate e aplicação de novos fundos. O Quadro 2 demonstra o orçamento do fluxo de caixa projetado.

Quadro 2: Orçamento do fluxo de caixa projetado

\begin{tabular}{|l|r|r|r|r|r|r|}
\hline & \multicolumn{1}{|c|}{ Janeiro } & \multicolumn{1}{|c|}{ Fevereiro } & \multicolumn{1}{c|}{ Março } & \multicolumn{1}{l|}{ Abril } & \multicolumn{1}{c|}{ Maio } & Junho \\
\hline Saldo Inicial & $\mathbf{3 . 0 0 0 , 0 0}$ & $\mathbf{9 . 3 0 0 , 0 0}$ & $\mathbf{5 . 6 0 0 , 0 0}$ & $\mathbf{4 . 0 6 0 , 6 4}$ & $\mathbf{2 . 8 0 2 , 4 0}$ & $\mathbf{3 . 7 0 4 , 8 0}$ \\
\hline Ingressos & $\mathbf{1 5 5 . 0 0 0 , 0 0}$ & $\mathbf{1 7 5 . 0 0 0 , 0 0}$ & $\mathbf{1 5 0 . 0 0 0 , 0 0}$ & $\mathbf{1 5 0 . 0 0 0 , 0 0}$ & $\mathbf{1 4 0 . 0 0 0 , 0 0}$ & $\mathbf{1 4 0 . 0 0 0 , 0 0}$ \\
\hline $\begin{array}{l}\text { Valores a } \\
\text { Receber }\end{array}$ & $155.000,00$ & $175.000,00$ & $150.000,00$ & $150.000,00$ & $140.000,00$ & $140.000,00$ \\
\hline Desembolsos & $\mathbf{1 0 8 . 2 0 0 , 0 0}$ & $\mathbf{1 0 8 . 2 0 0 , 0 0}$ & $\mathbf{1 1 1 . 2 0 0 , 0 0}$ & $\mathbf{1 1 1 . 2 0 0 , 0 0}$ & $\mathbf{1 1 1 . 2 0 0 , 0 0}$ & $\mathbf{1 1 1 . 2 0 0 , 0 0}$ \\
\hline Fornecedores & $9.500,00$ & $9.500,00$ & $9.500,00$ & $9.500,00$ & $9.500,00$ & $9.500,00$ \\
\hline $\begin{array}{l}\text { Despesas com } \\
\text { Pessoal }\end{array}$ & $40.000,00$ & $40.000,00$ & $42.000,00$ & $42.000,00$ & $42.000,00$ & $42.000,00$ \\
\hline Pró-labore & $10.000,00$ & $10.000,00$ & $11.000,00$ & $11.000,00$ & $11.000,00$ & $11.000,00$ \\
\hline $\begin{array}{l}\text { Taxas e } \\
\text { Contribuições }\end{array}$ & $8.200,00$ & $8.200,00$ & $8.200,00$ & $8.200,00$ & $8.200,00$ & $8.200,00$ \\
\hline $\begin{array}{l}\text { Simples } \\
\text { e demais } \\
\text { impostos }\end{array}$ & $18.500,00$ & $18.500,00$ & $18.500,00$ & $18.500,00$ & $18.500,00$ & $18.500,00$ \\
\hline $\begin{array}{l}\text { Despesas } \\
\text { Gerais }\end{array}$ & $22.000,00$ & $22.000,00$ & $22.000,00$ & $22.000,00$ & $22.000,00$ & $22.000,00$ \\
\hline $\begin{array}{l}\text { Saldo Líquido } \\
\text { do Mês }\end{array}$ & $\mathbf{4 9 . 8 0 0 , 0 0}$ & $\mathbf{7 6 . 1 0 0 , 0 0}$ & $\mathbf{4 4 . 4 0 0 , 0 0}$ & $\mathbf{4 2 . 8 6 0 , 6 4}$ & $31.602,40$ & $32.504,80$ \\
\hline $\begin{array}{l}\text { Saldo de } \\
\text { Caixa }\end{array}$ & $9.300,00$ & $5.600,00$ & $4.060,64$ & $2.802,40$ & $3.704,80$ & $2.994,80$ \\
\hline $\begin{array}{l}\text { Ingressos Não } \\
\text { Operacionais }\end{array}$ & & $\mathbf{4 0 . 1 6 0 , 0 0}$ & $\mathbf{1 1 0 . 6 0 0 , 6 4}$ & $\mathbf{1 5 1 . 0 4 1 , 7 6}$ & $\mathbf{1 9 1 . 3 6 2 , 4 0}$ & $\mathbf{2 1 9 . 6 3 5 , 0 4}$ \\
\hline $\begin{array}{l}\text { Empréstimos } \\
\text { Obtidos }\end{array}$ & & & & & & \\
\hline
\end{tabular}




\begin{tabular}{|c|c|c|c|c|c|c|}
\hline & Janeiro & Fevereiro & Março & Abril & Maio & Junho \\
\hline $\begin{array}{l}\text { Resgate de } \\
\text { Aplicação }\end{array}$ & & $40.000,00$ & $110.160,00$ & $150.440,00$ & $190.600,00$ & $218.760,00$ \\
\hline $\begin{array}{l}\text { Receita } \\
\text { Financeira }\end{array}$ & & 160 & 440,64 & 601,76 & 762,4 & 875,04 \\
\hline \multicolumn{7}{|l|}{$\begin{array}{l}\text { Taxa de Juros } \\
\text { Empréstimos }\end{array}$} \\
\hline $\begin{array}{l}\text { Desembolso } \\
\text { Não } \\
\text { Operacional }\end{array}$ & $40.500,00$ & $110.660,00$ & $150.940,00$ & $191.100,00$ & $219.260,00$ & $249.145,04$ \\
\hline \multicolumn{7}{|l|}{$\begin{array}{l}\text { Amortização } \\
\text { Empréstimos }\end{array}$} \\
\hline $\begin{array}{l}\text { Despesas } \\
\text { Financeiras }\end{array}$ & 500 & 500 & 500 & 500 & 500 & 500 \\
\hline $\begin{array}{l}\text { Aplicação } \\
\text { Financeira }\end{array}$ & $40.000,00$ & $110.160,00$ & $150.440,00$ & $190.600,00$ & $218.760,00$ & $248.645,04$ \\
\hline $\begin{array}{l}\text { Taxa de Juros } \\
\text { de Aplicação }\end{array}$ & & & & & & \\
\hline
\end{tabular}

Fonte: Dados projetados pelo autor (2019)

E relação aos Desembolsos não Operacionais, foram consideradas a Amortização de Empréstimos, Despesas Financeiras que ocorrem mensalmente por conta das movimentações, realização de Aplicações Financeiras mensais e as Taxas de Juros de Aplicação.

A partir da criação do Orçamento do Fluxo de Caixa descrito no Quadro 2 , a empresa poderá prever antecipadamente tudo o que tem para receber e os compromissos que possui para cumprir. Com esses dados em mãos, poderá se antecipar a alguma situação que poderá ocorrer mas, principalmente, poderá projetar os investimentos necessários para o semestre atendendo as demandas que poderão surgir.

\section{CONSIDERAÇÕES FINAIS}

Como visto em toda a fundamentação teórica, existem várias opções de criação de orçamento empresarial. Como cada organização tem sua forma de trabalho e as aptidões de sua equipe, os orçamentos apresentados podem ser usados em um formato diferente, atendendo especificamente os objetivos de acordo com cada empresa. Para o nicho deste estudo, que foi voltado para prestadores de serviço no desenvolvimento de software, a opção que melhor atendeu a demanda da empresa foi o desenvolvimento de um orçamento do fluxo de caixa para que possa projetar em um período futuro as demandas da empresa.

Por ser um mercado relativamente diferenciado, a venda de software acaba sendo uma venda mais técnica e direta, quando comparado a venda de produtos em geral. Assim sendo, a organização de um fluxo de caixa auxilia muito nos planejamentos da venda que precisam ser trabalhados minunciosamente para garantir que os investimentos sejam pontuais e o mais 
certeiro possível. Da mesma forma que na venda, é sempre necessário planejar também os demais setores visto que toda a empresa precisa continuamente de investimentos para o correto desenvolvimento das suas operações.

Conforme Nunes (2013), planejamentos internos são processos integrados efetuado pela direção e corpo de funcionários, o qual é criado com a intenção de enfrentar os riscos e fornecer segurança na execução da missão da empresa.

Desta forma, criar um planejamento orçamentário em uma empresa é de fundamental importância para que a mesma possa organizar as finanças e acompanhar os números no decorrer de um período de tempo.

Sabe-se que mesmo com todas as informações e atividades desenvolvidas para organização de empresas, muitas ainda não adotam nenhum tipo de prática para organizar suas finanças, o que limita-as muito. Isso pode ocorrer por inúmeros motivos mas, muitas delas por se considerarem pequenas acreditam que não possuem essa mas, indiferente do tamanho ou porte, ferramentas de gestão e organização pode auxiliar e muito a gestão e definir os rumos futuros da empresa.

O estudo em questão apresentou algumas limitações no que tange a existência de informações específicas para os levantamentos necessários. De maneira geral, as organizações tendem a ter informações bastante dispersas e isso dificulta a criação de uma estratégia para sugerir melhorias ou, propor criação de controles que venham ao encontro das necessidades das mesmas.

Para desenvolvimento de estudos futuros, pensa-se em criar outros indicadores que auxiliarão o processo de tomada de decisão, principalmente na criação de orçamentos para investimentos. A existência desse tipo de orçamento que promove uma organização interna para definição de recursos a serem aplicados não é muito comum em prestadores de serviços e isso auxiliará e muito as decisões de um determinado período de tempo.

\section{REFERÊNCIAS}

ATITUDE E NEGÓCIOS, Planejamento orçamentário para pequena empresa. Para que serve? Disponível em:< https://atitudeenegocios.com/planejamentoorcamentario/>. Acesso em: 10 jun. 2019.

DOURADO, Andréia Bicioni Pacheco. et al. Planejamento tributário: contribuições ao gerenciamento de tributos em uma empresa de vendas e locação de equipamentos de informática. Revista Estudo \& Debate, v. 25, n. 3, 2018. Disponível em: < http:// univates.br/revistas/index.php/estudoedebate/article/view/1717/1431>. Acesso em: 04 jul. 2019.

FIGUEIREDO, Anelice M. Banhara. Pesquisa cientifica e trabalhos acadêmicos. Chapecó: UCEFF Faculdades, $2^{\circ}$ ed. 2014. 
FIGUEIREDO, Sandra; CAGGIANO, Paulo Cesar. Controladoria: teoria e prática. 5. ed. São Paulo: Atlas, 2017.

FREZATTI, Fábio. Orçamento Empresarial: Planejamento e Controle Gerencial. $4^{\mathrm{a}}$ ed. São Paulo: Atlas, 2009.

HELENO, Renata Mendes. et al. Gestão de empresas familiares: um estudo de caso em uma empresa de materiais de construção. Revista Estudo \& Debate, v. 25, n. 3, 2018. Disponível em: <http:/ / univates.br/revistas/index.php/estudoedebate/ article/view/1856/1434>. Acesso em: 07 jul. 2019.

HOJI, Masakazu. Administração financeira e orçamentária: matemática financeira aplicada, estratégias financeiras, orçamento empresarial. São Paulo: Ed. Atlas, 2014.

LUNKES, Rogério João. Manual de orçamento. 2. ed. Reimpr. São Paulo: Atlas, 2008.

LIMA, Andréia de. Processo orçamentário como ferramenta de tomada de decisão. Monografia - MBA em Gestão Financeira e Controladoria, Universidade do Oeste de Santa Catarina, UNOESC, Videira, 2014.

MACEDO, Joel de Jesus. Análise de projeto e orçamento empresarial [livro eletrônico]. Curitiba: InterSaberes, 2014.

MARCONI, Marina de Andrade; LAKATOS, Eva Maria. Fundamentos de metodologia científica. 7. ed. São Paulo: Atlas, 2010.

NUNES, Eliane Pereira. et al. O controle interno como instrumento de gerenciamento na Universidade Federal do Pampa. Revista Estudo \& Debate, v. 20, n. 1, 2013. Disponível em: < http://www.univates.com.br/revistas/index.php/estudoedebate/ article/view/587>. Acesso em: 07 set. 2019.

OLIVEIRA, C. Orçamento de vendas: um estudo acerca das indústrias de um distrito industrial. Revista Gestão \& Planejamento. Salvador, n. 3, p. 487-500, set. 2014.

PADOVEZE, Clóvis Luís; TARANTO, Fernando. Orçamento empresarial: novos conceitos e técnicas. São Paulo: Pearson Education do Brasil, 2009.

PADOVEZE, Clóvis Luís. Orçamento empresarial. São Paulo: Pearson Education do Brasil, 2012.

QUANTOSOBRA, Planejamento Orçamentário: o que é e por que deve ser feito, 2018. Disponível em: < https://blog.quantosobra.com.br/planejamento-orcamentario/>. Acesso em: 25 mai.2019.

SANTOS, Izequias Estevam dos. Manual de métodos e técnicas de pesquisa científica. 12. ed. rev. E atual. Niterói, RJ: Impetus, 2016. 
SANVICENTE, Antônio Zoratto; SANTOS, Celso da Costa. Orçamento na administração de empresas: planejamento e controle.2. ed. - 18 reimpr. - São Paulo:Atlas, 2008.

SIMBER TECNOLOGIA, Pesquisa aponta crescimento no mercado de software, 2013. Disponível em:<https:/ / www.simber.com.br/erp/noticia-249-pesquisa-apontacrescimento-no- mercado-de-software>. Acesso em: 10 jun. 2019.

SOUZA, Acilon B. Curso de administração financeira e orçamento: princípios e aplicações. São Paulo: Ed. Atlas, 2014.

WEBER, Luan Veiga. Proposta de um sistema orçamentário econômico e financeiro aplicado a um posto de combustíveis. Trabalho de Conclusão de Curso - Curso de Ciências Contábeis, Universidade Regional do Noroeste do Estado do Rio Grande do Sul, UNIJUÍ, Ijuí, 2014.

YIN, Robert K. Estudo de caso: planejamento e métodos. 3 ed. Porto Alegre: Bookman, 2005. 